\title{
Prevalence and Severity of Temporomandibular Joint Disorders among Populations in Najran Province, Kingdom of Saudi Arabia
}

\author{
${ }^{1}$ Metaib A Aldhalai, ${ }^{2}$ Yahia AS Alyami, ${ }^{3}$ Yousef MB Al Haider, ${ }^{4}$ Mohammed K Aldhili, ${ }^{5}$ Dhafer AS Alyami \\ ${ }^{6}$ Saleh AS Alyami, ${ }^{7}$ Mohammed M Al-Moaleem, ${ }^{8}$ Nabiel Alghazali
}

\begin{abstract}
Aim: This study assessed the prevalence and severity of temporomandibular joint disorders (TMDs) in the absence or presence of teeth of participants in Najran region in comparison with other adult participants in other regions with respect to gender differences and age. Furthermore, it investigates the frequency of symptoms of temporomandibular joint (TMJ) by clinical examination.
\end{abstract}

Materials and methods: The total number of participants was 318 of both genders randomly selected for this study. The participants were divided into three age groups: 14 to 20, 21 to 40 , and $\geq 41$ years. The study was based on Fonseca's Anamnestic Index and its questionnaire, which is composed of 10 questions and classifies the severity of TMD. Clinical examination was performed for the patients to investigate the sign of TMJ dysfunctions. The obtained data were coded and entered into Statistical Package for the Social Sciences program for analysis using Chi-square test at significance level of $5 \%$.

Results: The participants with mild TMD dysfunction were 35.5\%, whereas 18.6 and $3.5 \%$ were classified as moderate and severe TMD dysfunction respectively. The most reported TMD problems were related to poor articulation of teeth (23.9 and $25.5 \%$ ), followed by frequent headache (15.1 and $33.6 \%$ ), then grinding of teeth (15.4 and 34.9\%) in "Yes" and "sometimes" answers respectively. The highest TMJ disorder was a frequent headache at $55.3 \%$, followed by TMJ clicking at $21.1 \%$. The remaining TMJ dysfunctions ranged between 11 and $13 \%$. There was no significant difference between TMDs and gender $(p \leq 0.306)$. However, the severity of TMDs increased with increasing age $(p \leq 0.001)$ and was associated with tooth loss ( $\leq \leq 0.000)$.

Conclusion: The majority of the participants had mild-tomoderate TMDs and they were found among the middle-age group. The severity of TMDs increased with age and was associated with tooth loss. No significant difference between males

\footnotetext{
${ }^{1,3}$ Department of Prosthodontics, Ministry of Health, Najran Kingdom of Saudi Arabia

${ }^{2,4-6}$ Ministry of Health Najran, Kingdom of Saudi Arabia

${ }^{7}$ Department of Prosthetics Dental Science, College of Dentistry Jazan University, Jazan, Kingdom of Saudi Arabia

${ }^{8}$ Department of Prosthetic, Dr. Sulaiman Al-Habib Hospital Riyadh, Kingdom of Saudi Arabia; Aleppo University, Aleppo Syrian Arab Republic
}

Corresponding Author: Mohammed M Al-Moaleem Department of Prosthetic Dental Science, College of Dentistry Jazan University, Jazan, Kingdom of Saudi Arabia, e-mail: drmoaleem2014@gmail.com and females was found. The most reported TMD problems were related to the poor articulation of teeth, frequent headache, and grinding of teeth, while a headache followed by clicking of TMJ was the highest clinical TMJ disorder.

Keywords: Clinical examination, Fonseca's questionnaire, Gender, Temporomandibular joint disorder.

How to cite this article: Aldhalai MA, Alyami YAS, Al Haider YMB, Aldhili MK, Alyami DAS, Alyami SAS, Al-Moaleem MM, Alghazali N. Prevalence and Severity of Temporomandibular Joint Disorders among Populations in Najran Province, Kingdom of Saudi Arabia. World World J Dent 2017;8(2):90-95.

\section{Source of support: Nil}

Conflict of interest: None

\section{INTRODUCTION}

Temporomandibular joint (TMJ) and temporomandibular joint disorders (TMDs) include a number of clinical conditions that involve the TMJ, the masticatory musculature, teeth, and associated structures or altogether. The TMD and other orofacial pain conditions represent significant important health problems. ${ }^{1}$

The prevalence of TMDs has differed from one country to another and has been reported to be in the range of 6 to $68 \%$ in various populations as mentioned by Poveda-Roda et $\mathrm{al}^{2}{ }^{2}$ with higher prevalence among women. ${ }^{3,4}$

The severity of TMD is low in young patients, ${ }^{5-7}$ but increases with age among adolescents up to young adulthood. Gaphor and Abdullah ${ }^{8}$ had concluded that TMD dysfunction was more among older age groups.

Many factors including loss of teeth, occlusal disharmony, emotional stress, masticatory muscle fatigue, parafunctional oral habits, and malfunction of structures adjacent to TMJ cause TMD dysfunction. ${ }^{9}$ The signs and symptoms of TMD are different and manifested clinically as pain in the TMJ and/or its surrounding tissues, limitation in mouth opening, joint sounds, mandibular deviation, clicking in the TMJ during movements and chewing disability, ${ }^{10}$ headache, ${ }^{11}$ and tenderness of muscles. ${ }^{12,13}$

Fonseca's questionnaire (FQ) is used for detecting the severity, signs, symptoms, and frequency of TMD; it offers 
the advantages of being cost-effective and an easy-to-use tool. Furthermore, it is simple and has less influence on the examiner and less variability in the measures. 714,15 Hence, it can be used by either general practitioners or epidemiologists. It is composed of 10 questions that screen the prevalence of TMD severity in the presence of pain in the TMJ, during chewing, and in the head and back. In addition, it evaluates parafunctional habits, limitations of the movements, joint clicking, an effect of malocclusion, and emotional stress sensation. ${ }^{14}$

Several studies investigated the frequency of TMD symptoms in different areas of the Kingdom of Saudi Arabia (KSA), but not in Najran region. ${ }^{16-22}$ The objectives of this retrospective study were to assess the prevalence and severity of TMD among different age groups and genders of Najran participants and to compare it with other populations in the presence and/or absence of tooth loss. Furthermore, investigation of the frequent signs and symptoms of TMJ by clinical examination was also carried out.

\section{MATERIALS AND METHODS}

\section{Patient Selection and Grouping}

This retrospective cross-sectional study was conducted in Najran region, KSA. An official approval for this study was taken from the director of the health affairs in the region. The participants for this survey were selected randomly from the patients who attended the dental centers and primary health-care governmental dental clinics. The study was carried out in the period between June and September 2016. The sample consisted of 318 participants (188 males and 130 females), with age ranging from 14 to 56 years. In accordance with the Declaration of Helsinki, consent forms were signed by all participants before establishing/starting to answer the questions and the clinical examination. The inclusions criteria were patients with/without missing teeth from each or both arches, patients of any age and without any systematic diseases or problems. The selected participants were divided into 3 groups according to age as 14 to 20, 21 to 40, and above 41 years respectively.

\section{Answering of Questionnaire}

This study was based on FQ and Fonseca's Anamnestic Index (FAI). The FQ was posted to the participants, and their feedback was returned. The FQ was used to assess TMD in a group of participants with different ages from the Najran region. This questionnaire was proposed by Da Fonseca et $\mathrm{al}^{14}$ in 1994 and is commonly used to classify TMD severity and provides a true full picture of TMD. It is composed of 10 questions as seen in Table 1 , which includes checking for the presence of pain in the head and back and TMJ, during chewing, parafunctional habits, movement limitations, joint clicking, and perception of malocclusion emotional stress sensation. Participants were told that the questions would be introduced to them and could be answered with the "Yes," "Sometimes," and "No" options, and only one answer should be marked for each question. For the detailed analysis of frequency and severity of TMD, the answer "Yes" was given a score of 10 and "Sometimes" was given a score of 5 , and the answer "No" was given a score of zero. The total maximum scores were out of a 100 after summing up of the 10 answers. There was no certain time limit to answer the question form and its submission, which meant that the participants involved in this study were not under any effect while filling the FQ.

\section{Clinical Examination}

All patients were examined by two trained dentists. The information regarding the clinical signs and symptoms of TMJDs including examination of TMJ for pain or clicking, tenderness of muscles of mastication, pain during eating, headache, and ear symptoms was collected. Absence or presence of teeth was recorded too.

Table 1: Response of the participants to Fonseca's 10 questions $(n=318)$

\begin{tabular}{|c|c|c|c|c|}
\hline \multirow[b]{2}{*}{ Question\# } & \multirow[b]{2}{*}{ Type of the question } & \multicolumn{3}{|c|}{ Response } \\
\hline & & Yes [n (\%)] & Sometimes [n (\%)] & No $[n(\%)]$ \\
\hline 1 & Is it hard for you to open your mouth? & $15(4.7)$ & $62(19.5)$ & $241(75.8)$ \\
\hline 2 & Is it hard for you to move your mandible from side to side? & $14(4.4)$ & $55(17.3)$ & $249(78.3)$ \\
\hline 3 & Do you get tired/muscular pain while chewing? & $18(5.7)$ & $82(25.8)$ & $218(68.6)$ \\
\hline 4 & Do you have frequent headaches? & $48(15.1)$ & $107(33.6)$ & $169(51.3)$ \\
\hline 5 & Do you have pain on the nape or stiff neck? & $23(7.2)$ & $80(25.2)$ & $215(67.6)$ \\
\hline 6 & Do you have earaches or pain in craniomandibular joints? & $25(7.9)$ & $64(20.1)$ & $229(72.0)$ \\
\hline 7 & $\begin{array}{l}\text { Have you noticed any TMJ clicking while chewing or when you } \\
\text { open your mouth? }\end{array}$ & $35(11.0)$ & $81(25.5)$ & $202(63.5)$ \\
\hline 8 & Do you clench or grind your teeth? & $49(15.4)$ & $111(34.9)$ & $158(49.7)$ \\
\hline 9 & Do you feel your teeth do not articulate well? & $76(23.9)$ & $81(25.5)$ & $161(50.6)$ \\
\hline 10 & Do you consider yourself a tense (nervous) person? & $47(14.8)$ & $139(43.7)$ & $132(41.5)$ \\
\hline
\end{tabular}




\section{Data Analysis}

The obtained total scores were compared with the FAI according to Da Fonseca et $\mathrm{al}_{1}{ }^{14}$ and the participants were classified per TMD dysfunction degrees, which were no TMD scores between 0 and 15 , mild TMD scores between 20 and 40, moderate scores between TMD 45 and 65, and severe TMD scores between 70 and 100. All the collected data were analyzed using a software package Statistical Package for the Social Sciences program version 20.1 for Windows (Inc., Chicago, Illinois, USA). Chi-square test was used to determine significance between categorical variables with different grouping factors. The statistical significance level was set at $<0.05$.

\section{RESULTS}

The total number of participants who had completed questionnaires and returned them were 318. Most of the participants were in the age group of 21 to 40 years $(176,63 \%)$ and were male participants (188, 59\%). Those who reported with tooth loss were 187 (58.8\%) (Table 2).

The distribution of participants according to the severity levels of TMD dysfunction based on the FAI is presented in Table 3. The participants who were classified as mild TMD dysfunction were $113(35.5 \%)$, whereas $59(18.6 \%)$ were classified as moderate TMD dysfunction and only $11(3.5 \%)$ were classified as having severe TMD dysfunction (Table 3).

Regarding the FQ as shown in Table 1, the most frequently reported TMD problems were related to poor

Table 2: Distribution of the samples according to gender and tooth loss

\begin{tabular}{ll}
\hline Factors & $n(\%)$ \\
\hline Gender & \\
Male & $188(59.1)$ \\
Female & $130(40.9)$ \\
Tooth loss & \\
Yes & $187(58.8)$ \\
No & $131(41.2)$ \\
\hline
\end{tabular}

articulation of teeth $(\mathrm{Q} 9:$ Yes $=23.9 \%$, Sometimes $=25.5 \%)$, followed by frequent headache $(\mathrm{Q} 4$ : Yes $=15.1 \%$, Sometimes $=33.6 \%)$, and then grinding teeth $(\mathrm{Q} 8:$ Yes $=15.4 \%$, Sometimes $=34.9 \%$ ). The "Sometimes" responses for Q10 (tense person) were the highest (43.7), while the "No" responses ranged from 41 to $78 \%$ for the 10 questions.

There were no associations between TMDs and gender. However, the severity of TMDs increased with an increased age and was strongly associated with tooth loss. Regarding age groups, most of the mild TMD, i.e., $65(36.9 \%)$, and moderate TMD, i.e., 29 (16.5\%), were found among participants between 21 and 40 years compared with under 20 years, i.e., $27(29.7 \%)$ and 1 (1.1\%) respectively. The highest severe TMD was among participants older than 40 years, i.e., 7 (13.7\%). Comparison of mean scores of answers showed no significant difference among gender ( $p \leq 0.306)$ for the 10 questions. However, it showed significant difference among tooth loss $(\mathrm{p} \leq 0.000)$ and age $(\mathrm{p} \leq 0.001)$ (Table 4$)$.

The responses to the clinical examinations are shown in Table 5. The highest frequently reported TMJ disorder was a headache, $176(55.3 \%)$, followed by TMJ clicking, $67(21.1 \%)$, while the remaining TMJ dysfunctions (tenderness of muscles of mastication and pain of TMJ, pain during eating and pain of ear) were (38) $11.9 \%$, (37) $11.6 \%$, (35) 11.0 , and (41) $12.9 \%$, respectively.

\section{DISCUSSION}

Najran is a city in southwestern KSA near the border with Yemen. It is the capital of Najran Province. Designated

Table 3: Frequency among the participants according to the severity of TMDs $(n=318)$

\begin{tabular}{ll}
\hline Type of TMD & Frequency (\%) \\
\hline No TMD & $135(42.5)$ \\
Mild or light TMD & $113(35.5)$ \\
Moderate TMD & $59(18.6)$ \\
Severe TMD & $11(3.5)$ \\
\hline Total & $318(100)$ \\
\hline
\end{tabular}

Table 4: Frequency of the severity of TMDs among different genders, age groups, tooth loss categories

\begin{tabular}{|c|c|c|c|c|c|}
\hline Variables & No TMD n (\%) & Mild TMD $n(\%)$ & Moderate TMD n (\%) & Severe TMD n (\%) & $p$-value \\
\hline \multicolumn{6}{|l|}{ Gender } \\
\hline Male & $85(45.2)$ & $59(31.4)$ & $35(18.6)$ & $9(4.8)$ & 0.306 \\
\hline Female & $50(38.5)$ & $54(41.5)$ & $22(16.9)$ & $4(3.1)$ & \\
\hline \multicolumn{6}{|c|}{ Age (years) } \\
\hline$\leq 20$ & $47(51.6)$ & $27(29.7)$ & $16(17.6)$ & $1(1.1)$ & $0.001^{*}$ \\
\hline $21-40$ & $77(43.8)$ & $65(36.9)$ & $29(16.5)$ & $5(2.8)$ & \\
\hline$\geq 40$ & $11(8.1)$ & $21(18.6)$ & $12(23.5)$ & $7(13.7)$ & \\
\hline \multicolumn{6}{|l|}{ Tooth loss } \\
\hline Yes & $61(32.6)$ & $73(39.0)$ & $44(23.5)$ & $9(4.8)$ & 0 \\
\hline No & $74(56.5)$ & $40(30.5)$ & $15(11.5)$ & $2(1.2)$ & \\
\hline
\end{tabular}

*(p $p 0.000) ;$ age $(p \leq 0.001)$ 
Table 5: Response to clinical examination of TMJ $(n=318)$

\begin{tabular}{lll}
\hline & \multicolumn{2}{c}{ Frequency } \\
\cline { 2 - 3 } Type of the clinical examination & $37(11.6)$ & $281(88.4)$ \\
\hline Presence of TMJ pain & $67(21.1)$ & $251(78.9)$ \\
Presence of TMJ clicking & $38(11.9)$ & $280(88.1)$ \\
Tenderness of muscles of mastication & $35(11.0)$ & $283(89.0)$ \\
Presence of pain during eating & $176(55.3)$ & $142(44.7)$ \\
Presence of a frequent headache & $41(12.9)$ & $277(87.1)$ \\
Presence of ear symptoms & & \\
\hline
\end{tabular}

a new town, Najran is one of the fastest growing cities in the kingdom; its population is 505,652. People without any education were $28 \%$ (females are more). Fortytwo percent of the population is 20 years or less, $51 \%$ between 20 and 40 years, and $7 \%$ are 50 years and more. Most of the females are homemakers and only a few of whom have higher education. Some of the males had no job.

This retrospective cross-sectional study was conducted to determine the frequency and severity of TMD among different age groups and genders in the presence of complete dentition and/or with a loss of some permanent teeth in Najran province using FQ and FAI. Overall, the participants showed mild-to-moderate TMD dysfunction in this study. This was in agreement with the international finding of other populations as mentioned by Bagis et $\mathrm{al}^{3}$ (Turkey), Nomura et $\mathrm{al}^{7}$ (Brazil), Wahid et $\mathrm{al}^{23}$ (Iran), Ebrahimi et $\mathrm{l}^{24}$ (Iran), Khan et $\mathrm{al}^{25}$ (Pakistan), and Chauhan et $\mathrm{al}^{26}$ (India). Comparison of these result was done with similar Saudi studies investigating the prevalence and severity of TMD and had used written questionnaires; these results were in agreement with the findings reported by Al-Harthy et al, ${ }^{17}$ Nassif et al ${ }_{1}^{18}$ Habib et al, ${ }^{27}$ and Kassab et al. ${ }^{28}$

As shown in Table 1, poor articulation of teeth (Q9) in "Yes," i.e., 23.9\%, was the most frequently reported TMD dysfunction; this is in agreement with the study of Habib et $\mathrm{al}^{27}$ (KSA). While a frequent headache showed $15.1 \%$ among participants for "Yes" and 33.6\% for "Sometimes," this totally agrees with results reported by Bagis et $\mathrm{al}^{3}$ (Turkey), Gaphor and Abdullah ${ }^{8}$ (Iraq), Khan et al ${ }^{25}$ (Pakistan), Omoregie and Okoh ${ }^{29}$ (Nigeria), and with local studies reported by Jagger and Wood ${ }^{22}$ and AbdelHakim et al. ${ }^{30}$ Regarding the grinding of teeth (Q8), it was $15.4 \%$ as "Yes" and $34.9 \%$ as "Sometimes" in the current study; this coincided with the finding of Habib et $\mathrm{al}^{27}$ (KSA) and Gaphor and Abdullah ${ }^{8}$ (Iraq). Q10 regarding being a nervous person had $14.8 \%$, as "Yes" and $43.7 \%$ as "Sometimes"; this coincided with the finding of Nomura et $\mathrm{al}^{7}$ (Brazil), Wahid et $\mathrm{al}^{23}$ (Pakistan), and the local study in Riyadh of Saudi Arabia by Habib et al. ${ }^{27}$

In many previous studies regarding TMD dysfunction and severity among genders, TMD problems were found to be more prevalent in females as compared with males in different committees as mentioned by Bagis et $\mathrm{al}^{3}$ (Turkey), Nomura et $\mathrm{al}^{7}$ (Brazil), Wahid et $\mathrm{al}^{23}$ (Iran), and Chuang ${ }^{31}$ (Taiwan). Other studies, however, including our study, recorded that there were no significant differences between males and females as that by Gaphor and $\mathrm{Abdullah}^{8}$ (Iraq) and Khan et $\mathrm{al}^{25}$ (Pakistan). This could be explained by presence of different races and their tolerance to certain diseases. However, this finding agreed with local studies conducted by Al-Harthy et $\mathrm{al}^{17}$ and Farsi, ${ }^{32}$ in the western region of KSA.

Regarding the age of the examined participants, our results totally agree with results of Al-Khotani et $\mathrm{al}^{16}$ and Akeel and Al-Jasser ${ }^{19}$ that the younger group of Saudi participants showed less TMJ dysfunction, such as a headache and joint sound. However, increasing age is strongly associated with increased TMD dysfunction as is evident in Table 4, and this agreed with the results of Bagis et $\mathrm{al}^{3}$ (Turkey). In addition, Bagis et al ${ }^{3}$ (Turkey) demonstrated a strong correlation between ages and missing teeth, which had a significant effect on the development of TMD symptoms. This was completely obvious in our findings as shown in Table 4.

Farsi and Alamoudi ${ }^{33}$ concluded that loss of primary teeth does not appear as an etiological factor for TMD development. Furthermore, Abdel-Hakim et $\mathrm{al}^{30}$ said that parafunctional habits do not affect dysfunction symptoms of TMD as tooth loss does among adolescents. Farsi et $\mathrm{al}^{34}$ concluded teeth loss had a role in the etiology of TMD.

In addition to the mentioned parameters of TMD dysfunctions, we also assessed the type of pain in the TMJ and the surrounded area by clinical examination. In the current study and as shown in Table 5, headache was significantly the highest TMJ dysfunction. This was in agreement with many similar Saudi studies. Those studies concluded that a headache had been considered as the most frequent symptom of TMD as mentioned by Al-Harthy et al, ${ }^{17}$ Nassif et $\mathrm{al}^{18}{ }^{18}$ Akeel and Al-Jasser, ${ }^{19}$ Zulqarnain et $\mathrm{al}_{,}{ }^{20}$ Nourallah and Johansson, ${ }^{21}$ Jagger and Wood, ${ }^{22}$ Abdel-Hakim et al, ${ }^{30}$ and Nassif and Talic. ${ }^{35}$

On the contrary, the second clinical finding was TMJ clicking or sound during opening and closing of the mouth. The same percentages were founded with Saudi studies mentioned by Zulqarnain et al, ${ }^{20}$ Jagger and Wood, ${ }^{22}$ and Farsi. ${ }^{32}$

A low frequency of TMJ pain/painful mouth opening and muscle tenderness was registered in this study. This totally agreed with the conclusions of Al-Harthy et al, ${ }^{17}$ Nassif et al, ${ }^{18}$ Akeel and Al-Jasser, ${ }^{19}$ Zulqarnain et al, ${ }^{20}$ and Nourallah and Johansson. ${ }^{21}$ However, Jagger and Wood $^{22}$ were those who concluded that muscle tenderness was high compared with other clinical findings; 
this could be related to the eating habits and type of consumed food.

A strength of this study is the randomization of the sample participants, which permits the generalization of the results to the population of Najran province of KSA. Another strength is that the same examiner performed the clinical examinations of all participants. The examiners were trained by a TMD specialist calibrated, which is an additional strength.

This study provided a small picture regarding the severity of TMDs and the clinical symptoms of TMJ disorders among the population in Najran region. However, long-term clinical studies should be conducted in this region using the recent diagnostic criteria for TMD, which include the biological/somatic axis I (physical examination), matched by the validation of different tools as well as the psychosocial axis II (self-report) in a diagnostic classification of chronic pain. ${ }^{36}$

\section{CONCLUSION}

From this cross-sectional study, the following conclusions can be drawn: The majority of the participants had mild-to-moderate TMDs dysfunction. Most of the mild, i.e., $36.9 \%$, and moderate TMD, i.e., $16.5 \%$, were found among participants between 21 and 40 years compared with other age groups. However, the severity of TMDs increased with increase in age group and was strongly associated with tooth loss. No significant difference between male and females in the 10 questions was seen. The most reported TMD problems were related to the poor articulation of teeth, frequent headache, and grinding of teeth. The highest "Sometimes" responses were among the tense patients. The highest frequent reported clinical TMJ disorders among participants were a frequent headache (55.3\%), followed by TMJ clicking (21.1\%).

\section{REFERENCES}

1. Sena MF, Mesquita KS, Santos FR, Silva FW, Serrano KV. Prevalence of temporomandibular dysfunction in children and adolescents. Rev Paul Pediatr 2013 Dec;31(4):538-545.

2. Poveda-Roda R, Bagan JV, Díaz Fernández JM, Hernández Bazán S, Jiménez Soriano Y. Review of temporomandibular joint pathology. Part I: classification, epidemiology, and risk factors. Med Oral Patol Oral Cir Bucal 2007 Aug;12(4): E292-E298.

3. Bagis B, Ayaz EA, Turgut S, Durkan R, Özcan M. Gender difference in prevalence of signs and symptoms of temporomandibular joint disorders: a retrospective study on 243 consecutive patients. Int J Med Sci 2012;9(7):539-544.

4. Al-Havaz A, Safari S, Mohammadpour N, Kheirkhah F, Motalleb-Nezhad M, Arian M. Relationship between temporomandibular joint dysfunction and psychological distress among students of Babol University of Medical Sciences and Technology, Iran. J Oral Health Oral Epidemiol 2015;4(2): 94-100.
5. Egermark I, Carlsson GE, Magnusson T. A 20-year longitudinal study of subjective symptoms of temporomandibular disorders from childhood to adulthood. Acta Odontol Scand $2001 \mathrm{Feb} ; 59(1): 40-48$.

6. Ahmed LI, Abuaffan AH. Prevalence of temporomandibular joint disorders among Sudanese University Students. JOHH 2016;4:2-5.

7. Nomura K, Vitti M, Oliveira AS, Chaves TC, Semprini M, Siéssere S, Hallak JE, Regalo SC. Use of the Fonseca's questionnaire to assess the prevalence and severity of temporomandibular disorders in Brazilian dental undergraduates. Braz Dent J 2007;18(2):163-167.

8. Gaphor SM, Abdullah MJ. Retrospective study of a series of 203 patients with temporomandibular joint disorders presenting at school of dentistry, university of sulaimani. Eur Sci J 2014 Mar;10(9):216-225.

9. Mehta NM. The role of interprofessional education in the management of temporomandibular and sleep disorders. Cranio 2013 Jul;31(3):159-160.

10. Cooper BC, Kleinberg I. Examination of a large patient population for the presence of symptoms and signs of temporomandibular disorders. Cranio 2007 Apr;25(2):114-126.

11. Vierola A, Suominen AL, Ikavalko T, Lintu N, Lindi V, Lakka HM, Kellokoski J, Narhi M, Lakka TA. Clinical signs of temporomandibular disorders and various pain conditions among children 6 to 8 years of age: the PANIC study. J Orofac Pain 2012 Winter;26(1):17-25.

12. Sönmez H, Sari S, Oksak Oray G, Camdeviren H. Prevalence of temporomandibular dysfunction in Turkish children with mixed and permanent dentition. J Oral Rehabil 2001 Mar;28(3):280-285.

13. Koh H, Robinson PG. Occlusal adjustment for treating and preventing temporomandibular joint disorders. J Oral Rehabil 2004 Apr;31(4):287-292.

14. Da Fonseca DM, Bonfante G, Valle AL, de Freitas SF. Diagnóstico pela anamnese da disfunção craniomandibular. Rev Gaucha Odontol 1994 Feb;42(1):23-24

15. Campos JA, Goncalves DA, Camparis CM, Speciali JG. Reliability of a questionnaire for diagnosing the severity of temporomandibular disorder. Rev Bras Fisioter 2009;13(1):38-43.

16. Al-Khotani A, Naimi-Akbar A, Albadawi E, Ernberg M, Hedenberg-Magnusson B, Christidis N. Prevalence of diagnosed temporomandibular disorders among Saudi Arabian children and adolescents. J Headache Pain 2016;17:41.

17. Al-Harthy M, Ekberg EC, Nilner M. Pain related temporomandibular disorders in adult Saudi Arabians referred for specialized dental treatment. Swedish Dent J 2010;34(3):149-158.

18. Nassif NJ, Al-Salleeh F, Al-Admawi M. The prevalence and treatment needs of symptoms and signs of temporomandibular disorders among young adult males. J Oral Rehabil 2003 Sep;30(9):944-950.

19. Akeel R, Al-Jasser N. Temporomandibular disorders in Saudi females seeking orthodontic treatment. J Oral Rehabil 1999 Sep;26(9):757-762.

20. Zulqarnain BJ, Khan N, Khattab S. Self-reported symptoms of temporomandibular dysfunction in a female university student population in Saudi Arabia. J Oral Rehabil 1998 Dec;25(12):946-953.

21. Nourallah H, Johansson A. Prevalence of signs and symptoms of temporomandibular disorders in a young male Saudi population. J Oral Rehabil 1995 May;22(5):343-347.

22. Jagger RG, Wood C. Signs and symptoms of temporomandibular joint dysfunction in a Saudi Arabian population. J Oral Rehabil 1992 Jul;19(4):353-359. 
23. Wahid A, Mian FI, Razzaq A, Bokhari SA, Kaukab T, Iftikhar A, Khan H. Prevalence and severity of temporomandibular disorders (TMD) in undergraduate medical students using Fonseca's questionnaire. Pak Oral Dent J 2014;34:3841.

24. Ebrahimi M, Dashti H, Mehrabkhani M, Arghavani M, Daneshvar-Mozafari A. Temporomandibular disorders and related factors in a group of Iranian adolescents: a crosssectional survey. J Dent Res Dent Clin Dent Prospects 2011 Fall;5(4):123-127.

25. Khan M, Khan A, Hussain U. Prevalence of temporomandibular dysfunction (TMD) among university students. Pak Oral Dent J 2015 Sep;35(5):382-385.

26. Chauhan D, Kaundal J, Karol S, Chauhan T. Prevalence of signs and symptoms of temporomandibular disorders in urban and rural children of the hilly northern state, Himachal Pradesh, India: a cross sectional survey. Dent Hypothesis 2013 Jan;4(1):21-25.

27. Habib SR, Al Rifaiy MQ, Awan KH, Alsaif A, Alshalan A, Altokais Y. Prevalence and severity of temporomandibular disorders among university students in Riyadh. Saudi Dent J 2015 Jul;27(3):125-130.

28. Kassab M, Bakry A, Salem WS. The incidence of temporomandibular joint disorders among dental students in Aljouf University, KSA. Int Invest J Med Sci 2015;2:5-11.
29. Omoregie OF, Okoh M. Pattern of temporomandibular pain dysfunction syndrome in a Nigerian population. J Med Invest Pract 2014 Jul;9(3):116-119.

30. Abdel-Hakim AM, Alsalem A, Khan N. Stomatognathic dysfunctional symptoms in Saudi Arabian adolescents. J Oral Rehabil 1996 Oct;23(10):655-661.

31. Chuang SY. Incidence of temporomandibular disorders (TMDs) in senior dental students in Taiwan. J Oral Rehabil 2002 Dec;29(12):1206-1211.

32. Farsi NM. Symptoms and signs of temporomandibular disorders and oral parafunctions among Saudi children. J Oral Rehabil 2003 Dec;30(12):1200-1208.

33. Farsi NM, Alamoudi N. Relationship between premature loss of primary teeth and the development of temporomandibular disorders in children. Int J Paediatr Dent 2000 Mar;10(1):57-62.

34. Farsi N, Alamoudi N, Feteih R, El-Kateb M. Association between temporomandibular disorders and oral parafunction in Saudi children. Odontostomatol Trop 2004 Jun;27(106):9-14.

35. Nassif NJ, Talic YF. Classic symptoms in temporomandibular disorder patients: a comparative study. Cranio 2001 Jan;19(1):33-41.

36. Oyarzo JF. Orofacial pain: a new approach to temporomandibular disorders. J Oral Res 2016 Aug;5(5):184-185. 